\title{
Status Update on the Threat of Babesiosis Returning to the United States
}

\author{
Tidwell Jason ${ }^{1}$, Vitek Christopher J ${ }^{2}$, Thomas Donald B ${ }^{1}$, and John M Thomas ${ }^{2 *}$ \\ ${ }^{1}$ United States Department of Agriculture, Cattle Fever Tick Research Laboratory, USA \\ ${ }^{2}$ Center for Vector Borne Disease, The University of Texas-Rio Grande Valley, USA
}

Submission: September 11, 2018; Published: September 24, 2018

*Corresponding author: John M Thomas, Center for Vector Borne Disease, The University of Texas-Rio Grande Valley, USA, Fax: (956) 665-3657; Tel: (956) 665-7147; Email: john.thomas@utrgv.edu

\begin{abstract}
Babesiosis is a hemolytic disease caused by protozoan parasites in the genus Babesia, transmitted through the saliva of infected ticks. The most economically important species, Babesia bigemina and B. bovis, infect cattle and are the etiological agents of bovine babesiosis. In the southern United States, eradication efforts directed against the tick vectors, Boophilus spp., began in the early 1900s. A quarantine zone in south Texas along the US/Mexico border was subsequently established following the eradication of the disease in the US. The permanent quarantine zone, spanning approximately 33\% of the total shared border between Texas and Mexico, has helped limit the reintroduction of the vector and disease, and reduced the incidence of the tick vectors. Further, a strict regimen of broad monitoring and surveillance activities coupled with a rapid response and systematic application of containment procedures under the joint jurisdiction of the Texas Animal Health Commission and the United States Department of Agriculture has proven effective in enforcing the permanent quarantine zone and preventing the emergence of babesiosis into the United States. However, the presence of exotic game animals has helped facilitate the spread of the tick vectors and, when coupled with expanding populations of native deer that can host the tick vectors, the prevalence of Boophilus spp. ticks suggests an increased risk of the return of bovine babesiosis to the United States. This mini-review will examine the efforts in south Texas during 2018 to prevent the spread of cattle fever ticks.
\end{abstract}

Keywords: Babesiosis; Cattle fever; Ticks; Eradication; Quarantine; Texas; Boophilus; USDA; TAHC

Abbreviations: PQZ: permanent quarantine zone; TAHC: Texas Animal Health Commission; USDA: United States Department of Agriculture

\section{Introduction}

Bovine babesiosis, also known as cattle fever, is a disease that results from infection with an Apicomplexan parasite in the genus Babesia that is vectored by ticks in the genus Boophilus [1]. The introduction of Boophilus ticks, Boophilus microplus and $B$. annulatus, to the United States likely first occurred when cattle and horses were brought over by Spanish settlers to North America [2]. These ticks can carry and transmitting the disease commonly referred to as bovine babesiosis, or Cattle Fever. Until the early 1900s, bovine babesiosis caused severe economic losses as the tick spread to previously-unexposed populations of cattle [3]. As a result, a program was established to eradicate the tick vector and prevent the re-introduction of the tick vector to the United States. In 1907, the Cattle Fever Tick Eradication Program established a national regimen of surveillance, treatment, and containment in the United States, working with affected states [4].

Over the next 40 years, these efforts were very successful in limiting the spread of bovine babesiosis such that, by 1943, the cattle fever ticks were declared to be eradicated from the US cattle population. Today, surveillance efforts rely upon trained inspectors who evaluate livestock such as cattle and horses (both resident or imported, as well as stray or smuggled animals from Mexico) by examining suspected animals in their entirety by hand to feel for ticks, a process known as 'scratching' [5]. All cattle within the Texas permanent quarantine zone (PQZ) are scratch-inspected and vaccinated against ticks on a yearly basis. Prior to removal from the quarantine zone, cattle must be scratch-inspected to certify that they are fever-tick free and are whole-body dipped in a bath of the organophosphate pesticide, coumaphos. Regulations are even stricter for imported cattle. In addition to the required coumaphos bath, if scratch inspection reveals the presence of any tick of any species, the entire shipment of cattle is denied entry to the US.

While the efforts of the Texas Animal Health Commission (TAHC) and the United States Department of Agriculture (USDA) have been very effective in monitoring and treating infected livestock animals and preventing babesiosis in the United States, the introduction of exotic game animals for recreational hunting has led to an increase in the incidence of cattle fever ticks in south Texas. A non-native species of antelope from India that was first introduced to Texas in the 1920s, the Nilgai (Boselaphus tragocamelus), is a known host for cattle fever ticks (Boophilus spp) [6]. In addition to the native deer population that 
is commonly infested with ticks, but are not carriers of babesiosis [7], Nilgai from Mexico are also known to be carriers of Babesia [8] and, as is common with many non-native animals, some Nilgai escaped their enclosures when they were introduced in the United States, and established large populations of wild Nilgai that range today across parts of south Texas, and northern Mexico [9]. This creates a potential 'perfect storm,' whereby untreated game animal populations are hosting the tick vectors and are found in overlapping regions with naïve cattle, thus increasing the likelihood of babesiosis.

\section{Discussion}

A PQZ to limit the initial spread of the vector [4] (Figure 1A) was enacted along the Texas/Mexico border. To date, this is the only operational and successful tick eradication program in the world. The PQZ stretches approximately 500 miles along the southern border of Texas and is monitored by the TAHC and the USDA. Analysis of the reporting data from the TAHC and USDA for 2018 shows the number of presumptive positive cases along the PQZ (Figure 1B), broken down on a county-by-county basis. Most of the cases of tick infestations as of July 2018 seem to cluster in four counties, two of which are adjacent to each other: CameronWillacy and Webb-Zapata. Given the proximity of these counties to Mexico, the detection of fever ticks is not surprising as these are regions where introductions occur frequently. So far in 2018, 123 stray Mexican cattle have been intercepted; 71 of them infested with fever ticks. However, one of the counties (Willacy) is well north of the Texas/Mexico border and the PQZ, suggesting that there may be another host that the tick vector utilizes, accounting for the increased spread of the vector, and potentially, Babesia. The TAHC and USDA surveillance efforts detected an unconfirmed case of Babesiosis in an ailing, debilitated Nilgai from the Cameron County border area, further suggesting that the likelihood of contact and spread of the tick vector from infected animals originating in Mexico to uninfected cattle and Nilgai herds in south Texas remains high. Additionally, while cattle are limited to certain pastures and range by fencing and other barriers that impede movement, Nilgai and deer are often able to move unimpeded between pastures and fields due to their ability to cross fencing and natural barriers such as rivers and embayments [10].

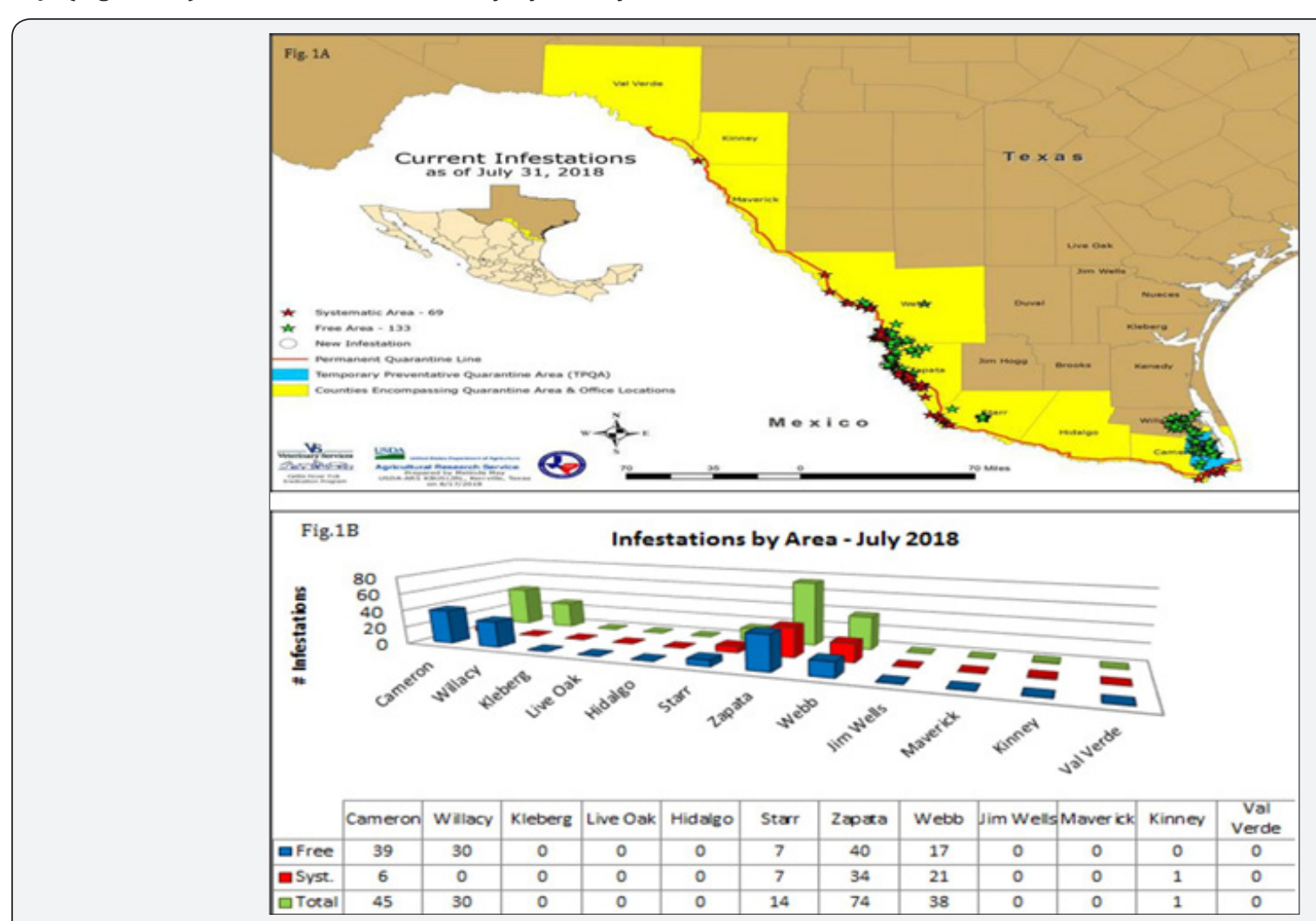

Figure 1: Surveillance of Cattle Fever and Tick Infestations along the Texas/Mexico Border. Surveillance efforts to limit the spread of the tick vector of Cattle Fever covers a range of $\sim 500$ miles.

1A: The eight counties that line the border were screened for tick infestations in July 2018

1B: outcomes are listed as the number of areas infested versus areas free of infestation.

Along with the surveillance and inspection efforts of livestock directly carried out by the TAHC and the USDA, additional detection efforts have recently begun targeting game animals. With the cooperation of the US Fish \& Wildlife Service and the Texas Department of Parks and Wildlife, these efforts rely on the examination of hides taken during the hunting season on private and public lands. Analysis of hides submitted during the 20172018 Texas hunting season showed a high level of tick infestation, among both native and exotic game animal populations (Table 1). Approximately $34 \%$ of native deer hides were infested with Cattle Fever ticks, compared to $46 \%$ of Nilgai hides submitted for inspection. 
Table 1: Detection of Cattle Fever Ticks on Native and Exotic Animals during the 2017/18 Season.

\begin{tabular}{|c|c|c|c|c|c|}
\hline \multirow[b]{2}{*}{ Hunt } & \multirow[b]{2}{*}{ Hunt Dates } & \multicolumn{2}{|c|}{ White-tailed Deer } & \multicolumn{2}{|c|}{ Nilgai } \\
\hline & & Clean & Infested & Clean & Infested \\
\hline Archery Hunt \#1 & November 17-21 & 4 & 6 & *5 & $* 1$ \\
\hline Archery Hunt \#2 & November 24-28 & 2 & 7 & 1 & 1 \\
\hline Archery Hunt \#3 (exotic only) & December 01-05 & & & 1 & 0 \\
\hline Firearm Hunt \#1 & December 08-10 & 22 & 6 & 3 & 3 \\
\hline Firearm Hunt \#2 & December 15-17 & 8 & 2 & 1 & 1 \\
\hline Firearm Hunt \#3 & Dec 22-Dec 24 & 4 & 4 & 1 & 3 \\
\hline Firearm Hunt \#4 & December 29-31 & 2 & 1 & $* * 7$ & $* * 9$ \\
\hline Firearm Hunt \#5 & January 05-07 & 5 & 0 & 6 & 8 \\
\hline Firearm Hunt \#6 (exotic only) & January 12-14 & & & 7 & 9 \\
\hline Firearm Hunt \#7 (exotic only) & January 19-21 & & & 1 & 2 \\
\hline Firearm Hunt \#8 (exotic only) & April 7-8 & & & 7 & 2 \\
\hline \multirow[t]{2}{*}{ Firearm Hunt \#9 (exotic only) } & April 14-15 & & & 9 & 3 \\
\hline & Totals & 47 & 26 & $* * * 49$ & $* * * 42$ \\
\hline
\end{tabular}

${ }^{*}$ One additional nilgai hunted; hunter did not bring in hide to inspect. Total hunted=7.

*One additional nilgai hunted; hunter did not bring in hide to inspect. Total hunted=17.

*** Two total additional nilgai hunted; hunters did not bring in hide to inspect. Total hunted=93.

\section{Conclusion}

The establishment and maintenance of the PQZ, along with robust surveillance and treatment efforts by the TDA and the USDA, have been effective in limiting the spread of Boophilus ticks into the United States. However, the frequency and severity of Boophilus outbreaks and infestations appears to be increasing. Beginning in 2014, areas in Cameron County north of the PQZ were found to be infested and, by 2015, premises in Willacy County were found to be infested. In both counties, more than half of the new infestations were detected on wildlife, either deer or Nilgai [11]. There are likely multiple factors that are facilitating the spread of the Boophilus tick vector, including changes in weather patterns and rainfall that are beneficial to the spread of the tick, economic and demographic factors that favor the increased importation of cattle, and the rise of acaricide resistance among Boophilus ticks [12].

It has been estimated that the seroprevalence of Babesia in Mexican cattle is $50 \%$, with some ranches reaching $90 \%$ or more [13]. Despite the high incidence of disease in Mexico, the United States imports over one-million head of cattle each year, further increasing the risk of re-introduction of babesiosis into the United States. When the known incidence of disease among Mexican livestock populations is already high, the constant threat of the re-introduction of babesiosis and Boophilus ticks from Mexico, coupled with the tick's ability to increase the range of its habitat by infesting game and exotic animals that move across the Texas/ Mexico border as well as the naiveté of Texas cattle populations to the disease, indicates that the protection extended to the US cattle and hunting industries by the PQZ and the USDA Cattle Fever Tick Eradication Program will continue to be needed. To date, the most robust mechanism of defense that is available to limit the spread of fever ticks appears to be constant surveillance, strict enforcement of quarantines, and intensive application of treatments, as enacted by the TAHC and the USDA, maintaining the PQZ as a barrier against the re-introduction of babesiosis to the United States.

\section{Acknowledgement}

The authors thank Ms. Melinda May for the creation of the map with the current infestations of cattle ticks and the USDA Cattle Fever Tick Eradication Program for the other figures. USDA is an equal opportunity provider and employer.

\section{References}

1. Bock R, Jackson L, De Vos A, Jorgensen W (2004) Babesiosis of Cattle. Parasitology 129: 247-269.

2. George JE, Davey RB, Pound JM (2002) Introduced ticks and tick-borne diseases: the threat and approaches to eradication. Veterinary Clinics Food Animal Practice 18: 401-416.

3. Dolman CE (1969) Texas cattle fever: A commemorative tribute to Theobald Smith. Clio Medica 4: 1-31.

4. Graham OH, Hourrigan JL (1977) Eradication programs for the arthropod parasites of livestock. Journal of Medical Entomology 13: 629-658.

5. Sutherst RW, Wharton RH, Utech KBW (1978) Guide to studies on tick ecology. CSIRO Australia Division of Entomology Technical Papers 14(14): 1-59.

6. Olafson PU, Thomas DB, May MA, Buckmeir BG, Duhaime RA (2018) Tick vector and disease pathogen surveillance of Nilgai antelope, Boselaphus tragocamelus, in southeastern Texas. 54(4): 734-744.

7. Ueti MW, Olafson PU, Freeman JM, Johnson WC, Scoles GA (2015) A virulent Babesia bovis strain failed to infect White-tailed Deer (Odocoileus virginianus). Plosone 10: 1-11.

8. Cardenas Canales EM (2011) Nilgai antelope in northern Mexico as a possible carrier for Cattle fever ticks and Babesia bovis and B. bigemina. Journal of Wildlife Diseases 47: 777-779. 
9. Sheffield WJ, Fall BA, Brown BA (1983) The Nilgai antelope in Texas. Texas Agricultural Experiment Station RM13, Texas A\&M University, Kingsville, TX. pp. 102.

10. Foley AM (2017) Movement patterns of nilgai antelope in south Texas: implications for cattle fever tick management. Preventive Veterinary Medicine 146: 166-172.

11. Lohmeyer KH, May M, Thomas DB, Perez-de-Leon AA (2017) Implication of Nilgai antelope (Artiodactyla: Bovidae). In: reinfestations of

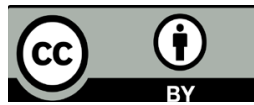

This work is licensed under Creative Commons Attribution 4.0 License

DOI: $10.19080 / J D V S .2018 .07 .555723$
Rhipicephalus (Boophilus) microplus (Acari: Ixodidae) in south Texas: a review and update. Journal of Medical Entomology 55: 515-522.

12. Adalberto A Pérez de León (2010) One Health approach to identify research needs in bovine and human babesiosis: workshop report. Parasites \& Vectors 3 (36):1-12.

13. Lopez M (2008) Infection and seroconversion of susceptible animals introduced into a Babesiosis endemic area. Annals New York Academy of Science 1149: 131-135.

Your next submission with Juniper Publishers will reach you the below assets

- Quality Editorial service

- Swift Peer Review

- Reprints availability

- E-prints Service

- Manuscript Podcast for convenient understanding

- Global attainment for your research

- Manuscript accessibility in different formats

( Pdf, E-pub, Full Text, Audio)

- Unceasing customer service

Track the below URL for one-step submission https://juniperpublishers.com/online-submission.php 